\title{
A cidade e os livros: ou como formar uma biblioteca?:notas históricas sobre a primeira Biblioteca Pública de São Paulo (1825 - 1887)
}

Marisa Midori Deaecto

Doutora em História (USP); Docente da Escola de Comunicações e Artes da Universidade de São Paulo (USP).

http://dx.doi.org/10.1590/1981-5344/3238

O presente artigo propõe uma história da primeira Biblioteca Pública da cidade de São Paulo através da leitura de seus catálogos bibliográficos. $O$ primeiro registro da coleção dessa instituição data de 1826 e consiste em um inventário dos livros antes pertencentes ao convento de $S$. Francisco, ao qual se somaram os volumes conformavam a biblioteca do bispo $D$. Mateus de Abreu Pereira, falecido em 1824. Em 1827, a biblioteca será anexada à Faculdade de Direito. A partir desse momento, interessa observar como se deu a conformação de um novo acervo, voltado para a literatura jurídica e, ao mesmo tempo, investiga-se a relação da Biblioteca com as livrarias da cidade. O estudo se encerra em 1887, quando da publicação do primeiro catálogo impresso dos livros da biblioteca da Faculdade de Direito.

Palavras-chaves: biblioteca, literatura jurídica, comércio de livros, São Paulo

\section{The city and the books: or how to form a library ?: historical notes on the first Public Library of São Paulo (1825 -} 1887)

The present article proposes a history of the first Public Library of the city of São Paulo through the reading of its bibliographic catalogs. The first record of the collection of this institution dates from 1826 and consists of an inventory of books previously belonging to the convent of St. Francis, to which were added the volumes conformed 
the library of Bishop Mateus de Abreu Pereira, who died in 1824. In 1827, the library will be attached to the Faculty of Law. From that moment on, it is interesting to observe how a new collection was developed, focused on legal literature and, at the same time, investigated the relationship between the Library and the city's bookstores. The study ends in 1887, when the first printed catalog of the books of the library of the Faculty of Law was published.

Keywords: library, legal literature, bookstores, São Paulo city

\section{Introdução}

Fundada em 1825, a primeira Biblioteca Pública da cidade de São Paulo nasce no contexto da independência do Brasil e do projeto de organização de suas instituições político-administrativas. Trata-se, portanto, de um projeto a um só tempo de natureza cultural e política, com o objetivo de integrar as províncias ao poder central e, ao mesmo tempo, fomentar as atividades do espírito em meio a população. A esses dois fatores, é preciso assinalar que uma instituição de leitura pública, administrada pelo governo central e laica viria a fazer frente às bibliotecas religiosas instaladas na maior parte das cidades brasileiras ${ }^{1}$.

$\mathrm{Na}$ época da Independência, São Paulo não passava de um burgo de 20.000 habitantes, apresentando dimensões e aspectos arquitetônicos muito simplórios. Malgrado esses fatores, a vila apresentava um sítio geográfico privilegiado, funcionando como ponto de cruzamento de rotas importantes que ligavam o litoral à hinterland ou às capitanias do Sul ${ }^{2}$. Além das trocas a grosso ou a retalho que fizeram a fortuna de algumas famílias locais, em São Paulo se instalaram desde os primórdios do período colonial as ordens religiosas que impulsionaram as funções espirituais e educacionais da cidade. Logicamente, clérigos, monges e frades não se furtaram em organizar por aquelas paragens suas bibliotecas.

Não estranha o fato da primeira Biblioteca Pública da cidade ter se constituído a partir de dois importantes fundos religiosos. A parte mais rica, compondo 3196 volumes, corresponde à biblioteca dos

\footnotetext{
${ }^{1}$ Antes, foram oficialmente inauguradas as bibliotecas públicas da Bahia, em 1811, e a do Rio de Janeiro, em 1814. Cf. Rubens Borba de Moraes, Livros e bibliotecas no Brasil Colonial. Rio de Janeiro, Livros Técnicos e Científicos; São Paulo, Secr. da Cultura, Ciência e Tecnologia do Estado de São Paulo, 1979, p. 143-144; Gilberto Vilar de Carvalho, Biblioteca Nacional (1807-1990) - Biografia. Rio de Janeiro: Irradiação Cultural, 1994, p. 40.

2 Maria Luiza Marcílio, La Ville de São Paulo. Peuplement et population, 1750-1850 d'après les registres paroissiaux et les recensements anciens. Paris: PUF, 1968.
} 
Franciscanos ${ }^{3}$. A ordem se estabeleceu na cidade em meados do século XVII e o trabalho dos frades junto a população lhes valeu uma certa notoriedade. No final do século XVIII eles organizarão cursos de Filosofia, Teologia e Línguas (francês e latim) abertos ao público em geral, ao mesmo tempo que asseguravam aulas voltadas para a formação técnica, no domínio da Geometria aplicada à construção civil. Leis restritivas à organização das ordens religiosas nos domínios portugueses, as quais vinham se pronunciando desde os tempos do Marquês de Pombal (1699$1782)^{4}$, tocaram diretamente a vida dos religiosos paulistas e promoveram o esvaziamento de seus conventos e mosteiros. Assim, as dificuldades de recrutamento de novos missionários, a falta de recursos materiais e a interdição das atividades de ensino esvaziaram pouco a pouco o convento dos franciscanos na cidade de São Paulo ${ }^{5}$.

A outra parte da coleção se deve a uma compra de ocasião, dado o falecimento do bispo D. Mateus de Abreu Pereira, em 1824. Nascido em Funchal, em 1741, ele faz sua licença em Direito Canônico, na Universidade de Coimbra e, após algumas missões, assumirá, em 1794, a diocese de São Paulo. Chegando na cidade três anos mais tarde, instalase em uma chácara no então distante bairro da Glória, onde organiza uma boa biblioteca e um centro de estudos destinados aos jovens seminaristas e pessoas próximas ${ }^{6}$. Após seu falecimento, o presidente de província se esforça para adquirir sua coleção de livros, a qual conformava 1059 volumes, vislumbrando já a construção de uma biblioteca pública. E como a biblioteca do bispo não era considerada um bem pessoal, mas pertencente à Mitra, cuja formação remonta aos esforços do bispo que o antecedeu, D. Fr. Manuel da Ressurreição (1718-1789), não foi difícil levar todo o acervo à venda pública, o que possibilitou sua aquisição pelo Ministério do Império, para uso da província?.

O status da Biblioteca Pública mudará muito rapidamente, em 1827, quando ela passará a ser gerida pela Faculdade de Direito - recéminstalada na cidade. Data de 1826, portanto, de um ano antes da

${ }^{3}$ Cf. Marisa Midori Deaecto, Império dos livros. Instituições e práticas de leituras na São Paulo oitocentista. São Paulo, Edusp, 2011, p. 87.

${ }^{4}$ Basilio Rower, Páginas da história franciscana, Petrópolis: Vozes, 1971, p. 134; Aurea Adão, Estado absoluto e ensino das primeiras letras. Escolas Régias (1772-1794), Lisboa: Calouste Gulbenkian, 1997.

${ }^{5}$ Proclamado Imperador do Brasil em 1822, D. Pedro I deve unificar o território e consolidar as instituições político-administravas da jovem nação. Nos primeiros anos de governo ele precisou enfrentar o perigo de desagregação territorial, em um quadro marcado por guerras provinciais, campanhas separatistas e movimentos fieis à Coroa portuguesa. Após 1824, quando da outorga da primeira carta constitucional, observa-se um movimento de centralização do poder e da publicação de leis de cunho liberal, como aquela que preconizava a tomada dos bens da Igreja pelo Estado, em 1826. Não houve, todavia, um movimento radical, comprável ao que vamos assistir em Portugal, em 1834, quando a confiscação dos bens conventuais resulta na destruição de suas bibliotecas e no aquecimento do comércio alfarrabista na cidade de Lisboa. Cf. Artur Anselmo, Estudos de história do livro, Lisboa, Guimarães Editora, 1997.

${ }^{6}$ Homem de seu tempo, fiel aos princípios da fisiocracia, o bispo não negligenciava as leituras religiosas, nem aquelas de uso prático. Ele mesmo desenvolveu em sua chácara o cultivo do bicho da seda. De sua coleção destacamos alguns títulos afins, por exemplo, Dissertações filosófico-políticas sobre o trato das sedas, pelo Pe. José Antônio de Sá, 1 v., in- $8^{\circ}$; Diccionario Universal de Agricultura, etc. etc., pelo Ab. Rozier, trad. em espanhol por D. J. A. Guerra, broch., in $-4^{\circ}, 1$ vol.; e Cartas de hum cultivador americano, por M. Sto. John, 3 v., in- $8^{\circ}$. Cf. Myriam Ellis, "Documentos sobre a primeira biblioteca oficial de São Paulo", Revista de História, São Paulo, 1957, n 30, p. 400-447.

7 De acordo com o Presidente de Província, Lucas Antonio Monteiro de Barros, o bispo havia expresso em testamento o desejo de converter sua coleção em biblioteca pública. Cf. Myriam Ellis, op. cit, p. 399. 
mudança institucional, a primeira lista dos livros que de compõe a coleção.

\section{Do público ao jurídico}

A história da primeira biblioteca pública de São Paulo apresenta, nesse sentido, duas etapas distintas: no primeiro período, de curta duração (1825-1827), a instituição foi fundada e instalada em parte do convento dos franciscanos; num segundo momento, bem mais extenso (1827-1887), temos a organização da biblioteca, alinhada a uma cultura jurídica dominante.

Se, de um lado, o paradigma da biblioteca pública se insere em um movimento mais amplo da Ilustração, tal como o vemos se desenvolver nos Estados Unidos, no contexto da Independência, mas também na Europa, na França de modo especial - se bem que o conceito de "biblioteca do povo", na conjuntura revolucionária e, em seguida, de "biblioteca municipal", aplique-se melhor a este país8 - o que observamos, na prática, é uma tendência à especialização da coleção paulistana segundo os padrões da bibliografia jurídica.

Também as regras de funcionamento da instituição paulistana se adequam às condições gerais do meio. Em 1821, a sala de leitura da biblioteca dos franciscanos era franqueada "para as gentes de letra da cidade" das $8 \mathrm{~h}$ às $11 \mathrm{~h}$ da manhã. Era possível tomar os livros de empréstimo, pois certos volumes serão reclamados mais tarde, em 1826, pelo primeiro bibliotecário da instituição pública, Fr. José Antonio dos Reis, quando da preparação de seu primeiro catálogo. Alguns desses antigos hábitos serão conservados pela instituição, não sem problemas, como podemos ler no documento abaixo:

Pelo Avizo de 12 de Setembro do anno próximo passado mandou Sua Magestade o Imperador communicar a este Governo, que constando o incrível abuzo de sahirem da Bibliotheca Publica desta Imperial Cidade à titulo de empréstimo Tratados inteiros, e também volumes separados, que muitas vezes se não restituão, prejudicando-se deste modo aquelle estabelecimento, e contrariando-se os utilíssimos fins de sua instituição [...] [Lucas Antonio Monteiro de Barros, Presidente da Província de São Paulo, 31 jan. 1827] $]^{9}$.

Do ponto de vista ideológico, os discursos sobre a biblioteca, e mais geralmente sobre a Faculdade de Direito, sintetizam as contradições reconhecidas no nível político: fala-se de liberalismo, mas este se insere em uma monarquia fortemente centralizadora. A biblioteca é pública, de inspiração liberal, mas a prática, como vimos, estava longe de ser

\footnotetext{
${ }^{8}$ Os modelos de abertura são múltiplos e dizem muito sobre sua época, sobre sua natureza e sobre o público que a frequenta, como observa Frédéric Barbier, "Em France: le prive et le public, ou qu'est-ce qu'une bibliothèque des Lumières?". Un'istituzione dei Lumi: la biblioteca. Teoria, gestione e pratiche biblioteconomiche nell'Europa dei Lumi. Parma: Museo Bodoniano, 2012, p. 11-28.

${ }^{9}$ Myriam Ellis, op. cit, pp. 401 e 405-406.
} 
republicana ${ }^{10}$, preservando-se, antes, o sistema de privilégios de alguns sobre os bens públicos.

Por outro lado, a redefinição do estatuto da biblioteca, em 1827, não implicava a exclusão dos antigos leitores. O único documento que dá conta da reação dos habitantes diante dessas mutações diz respeito à defesa da integridade física do convento, cujo imóvel foi parcialmente doado para o poder público visando a instalação da Biblioteca e, ao final de dois anos, da Faculdade. Uma petição foi apresentada ao Imperador, sob o título: "Representação de numerosos cidadãos de São Paulo a d. Pedro I, imperador do Brasil, solicitando fosse revogada a portaria que determinava a cessão de todo o convento de São Francisco em favor da Faculdade de Direito de São Paulo e a remoção de seus religiosos. [São Paulo, 1828, doc. assim. por Antonio Joaquim de Abreu Pereira e muitos outros]"11. Todavia, a construção do convento foi efetivamente dividida, assim como seu acervo bibliográfico - e essa configuração se mantém até nossos dias.

De acordo com o catálogo preparado pelo Fr. José Antonio dos Reis, pode-se observar que a coleção apresenta, para além de títulos religiosos, um repertório muito significativo de obras sob a rubrica História Universal, tanto de livros oriundos da coleção episcopal, quanto do fundo dos franciscanos $(22 \% ; 17 \%)$. A segunda rubrica mais expressiva em termos quantitativos aparece como $(23 \% ; 17 \%)$, seguida dos títulos reagrupados em Filosofia, Matemática, História Natural e Física (14\% ; $5 \%)^{12}$. De modo geral, o que se observa é uma coleção muito heterogênea, cujos estudos envolvem questões relevantes para a vida intelectual de uma pequena cidade provinciana na passagem do século XVIII para o XIX.

Após esse longo preâmbulo, voltemos nossos olhos para a Biblioteca, no momento de sua segunda fundação, em 1827. Pelas razões expostas, era de se esperar que o fundo ali encontrado não se adequasse muito às exigências de um curso superior em formação. O que se possuía no campo do Direito, mais precisamente do Direito Natural e Civil, correspondia a apenas $6 \%$ e $9 \%$ dos acervos do bispo e dos franciscanos, respectivamente. As Ordenações afonsinas, manuelinas e filipinas, ou seja, o conjunto das leis e regulamentos do reino português durante 0 Antigo Regime, compunham esse modesto acervo. Dentre os autores franceses, notam-se as obras de Mably, Direito público da Europa e $A$ Legislação, o Princípio das leis, ambos os títulos anotados em português. É provável que os títulos fossem muito familiares ao bibliotecário, o que justificaria a tradução imediata dos títulos, pois desconhecemos edições

\footnotetext{
${ }^{10}$ Sobre o modelo de public library, cf. Edward Bansfield, « Needed : a public purpose », dans The Public library and the city, Boston (Mass.), M.I.T. Press, 1966, p. 104; The American Peoples Encyclopedia. A modern reference work, New York, Grolier Inc., 1968. [articles «Library » and « Public »] ; Anne-Marie Bertrand, Bibliothèque publique et public library : essai de généalogie comparée, Villeurbanne, ENSSIB, 2010.

${ }^{11}$ Anais da Biblioteca Nacional, Rio de Janeiro, 1953, $\mathrm{n}^{\circ} 74$, v. II.

${ }^{12}$ Sob essa rubrica, destacamos a Bibliothèque de l'homme public de Condorcet e uma coleção (completa?) da L'Encyclopédie méthodique. Myriam Ellis, op. cit.; Marisa Midori Deaecto, O Império dos livros, op. cit., pp. 76-98.
} 
contemporâneas vertidas para o português, embora o autor constasse no programa do curso jurídico da Universidade de Coimbra.

Tal observação nos convida a refletir sobre o tipo de catálogo que se encontra em vias de confecção nesse primeiro momento da história da Biblioteca, cujos parâmetros pareciam longe daqueles observados na mesma época por algumas bibliotecas especializadas europeias. Em primeiro lugar, o sistema de catálogos e listas manuscritas se mantém, devendo-se considerar, nesse caso, que a primeira tipografia seria instalada na cidade apenas em 1828, por obra de um particular. Sobre a função das primeiras listas, deve-se dizer que elas tinham mais efeito para registro patrimonial, do que para a consulta pública, embora o bibliotecário tivesse o cuidado de separar os exemplares em rubricas ou áreas do conhecimento e de anotar seus respectivos formatos, o que, sabemos, pode indicar o lugar do livro nas estantes das antigas bibliotecas. Não há, contudo, o propósito de fazer do inventário um catálogo sistemático dos livros constantes na Biblioteca Pública, bastante observar que as informações bibliográficas são incompletas e, na maior parte das vezes, os títulos são traduzidos e abreviados. É o que vemos no excerto abaixo, segundo reprodução fac-símile realizada por Myriam Ellis. 


\section{Escript. Sagráda, e St.os Padres}

\begin{tabular}{|c|c|}
\hline $\begin{array}{l}\text { Thesouro Biblico }- \text { pr. Merz } \ldots \ldots \ldots \text { Em } \\
\text { Novo Testam.to conforme ao Exemp.r do Va- } \\
\text { ticano pr. } * * \ldots \ldots \ldots \ldots \ldots \ldots \ldots \ldots \ldots\end{array}$ & $\begin{array}{l}\text { Estão - faltão. } \\
4^{\circ} \text { vol. } 1 \text { (1) }\end{array}$ \\
\hline Dito em Grego e Latim, pr. Leusden ........ & $8 . .^{\circ}$ vol. 1 \\
\hline Apparato Biblico, pr. Lamy ........... & 4. vol. 1 \\
\hline $\begin{array}{l}\text { Antigo, e Novo Testamento, pr. Calmet ... } \\
\text { Analize dos Evang.s pr. hu. Presbytero do }\end{array}$ & fol. vol. 11 \\
\hline $\begin{array}{l}\text { Or. de Is. } \ldots \ldots \ldots \ldots \ldots \ldots \ldots \ldots \\
\text { D.a Critico-pratica do L.o dos Psalm.s }- \text { pr. }\end{array}$ & $8 .^{\circ}$ vol. 8 \\
\hline 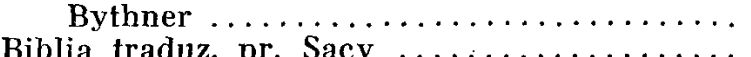 & $8 .^{\circ}$ vol. 1 \\
\hline $\begin{array}{l}\text { Biblia traduz. pr. Sacy } \ldots \ldots \ldots \ldots \ldots \ldots \ldots \ldots \\
\text { Novo Testam. illustrado pelo Thalmud, e an- }\end{array}$ & $8 .^{\circ}$ vol. 12 \\
\hline $\begin{array}{l}\text { tig.des dos Judeos, pr. Gerhard } \ldots \ldots \ldots \\
\text { Comentario solre a concord. dos } 4 \text { Evang.s e }\end{array}$ & $4 .^{\circ}$ vol. 2 \\
\hline $\begin{array}{l}\text { Apparato Chronologico, \& pr. Lamy } \ldots \\
\text { Obras de S. Cypriano } \ldots \ldots \ldots \ldots \ldots \ldots \ldots \ldots\end{array}$ & $\begin{array}{l}4 .{ }^{\circ} \text { vol. } 2 \\
\text { fol. vol. } 1\end{array}$ \\
\hline 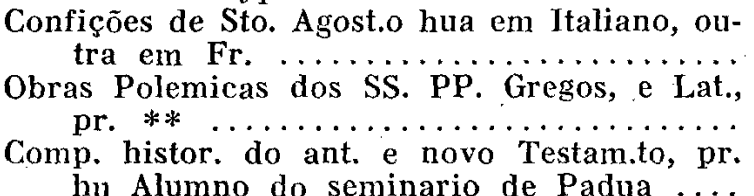 & $\begin{array}{l}8 .^{\circ} \text { e } 12 .^{\circ} \text { vol. } \\
8 .^{\circ} \text { vol. } 18\end{array}$ \\
\hline
\end{tabular}

Os Seg.tes pertencem ao Conv.to de S. Fran.co

Missa ordinaria - de Lyrãno ............ Huma concordata Biblica, do m.mo ........

Biblia, de Marianna $\ldots \ldots \ldots \ldots \ldots \ldots \ldots$.

Biblica, e Concord. de Duhamél .........

Biblia - do Cardeál Hugo ..............

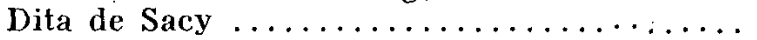

Vulgata Lat. 3 jogos . . . . . . . . . . . . .

Biblia de Sabatier .................

Da. traduz. pelo Pe. Antonio Per.a ........

Novo Testam. traduz. pelo mesmo ........

Os Psalmos Traduz. pr. Bertthier ........

Biblia de Calmet $\ldots \ldots \ldots \ldots \ldots \ldots \ldots \ldots$

Diccion. histor, prolegom. \& plo. mesmo ....

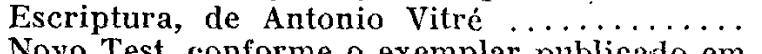

Novo Test. conforme o exemplar publicado em

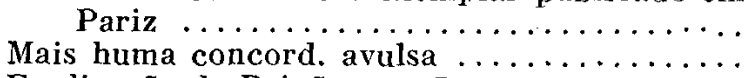

Explicação da Paixão, por Duguet ............
Comentar as Epist. de S. Paulo, pr. Theophilato

Comentar as Epist. de S. Paulo, pr. Theophilato
Apologia da Vulg.ta Lat. pr. F. Joaq.m d'Aze-

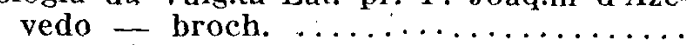

Coment. in Evang. et de Chr.i figura, por Baeza

Do. allegorico de Chr.o figurato p.lo m.mo ..

fol. vol. 5

fol. vol. 1 fol. vol. 2 fol, vol. 3 fol. vol. 8 $8 .^{\circ}$ vol. 32 $8 .^{\circ}$ vol. 3 fol. vol. 3 $4 .^{\circ}$ vol. 7 $8 .^{\circ}$ vol. 6 8. vol. 5 fol. vol. 9 fol. vol. 6 $4 .^{\circ}$ vol. 2

8. vol. 1 fol. vol. 1 $8 .^{\circ} \mathrm{V}$

$8 .^{\circ}$ vol. 1

fol. $\mathrm{vol}$

fol. vol. 3

fol. vol. 1

Figura 1. Primeiro inventário dos livros realizado pelo Bibliotecário Pe. José Antonio dos Reis, 1826

Fonte: Myriam Ellis, "Documentos sobre a primeira biblioteca oficial de São Paulo", Revista de História, São Paulo, 1957.

Se considerarmos as disciplinas que conformam a classificação da maior parte dos catálogos sistemáticos ou metódicos da época, veremos que nosso bibliotecário se esforça em manter o padrão classificatório na lista que redige. O esquema abaixo reproduz as seções do catálogo, tal como elas aparecem no mesmo documento (supracitado): 


\section{Classificação sistemática ou metódica Segundo 5 classes DE DISCIPLINAS (SÉCULO XVIII)}

\section{Teologia}

Escrituras Sagradas e Santos Padres

Liturgia

Sermonários

Teologia Natural, Dogmática e Moral Teologia Mística

Jurisprudência

Direito Canônico

Direito Natural e Civil

\section{Ciencias e artes}

Filosofia, Matemática, História Natural e Física

\section{Belas Letras}

Retórica e Poética

Dicionários e Artes das Línguas

\section{Geografia \& História}

História Universal e Particular

Miscelânea historia \& Geografia

Figura 2. Estrutura do inventário

Fonte: Esquema elaborado pela autora a partir da transcrição do documento por Myriam Ellis, "Documentos sobre a primeira biblioteca oficial de São Paulo", Revista de História, São Paulo, 1957.

Uma vez concluído o inventário, era mister investir em obras atuais, que revelassem a vocação jurídica daquela nova instituição. É o que vemos no comentário extraído do recenseamento de 1836:

Possue esta Academia uma bibliotheca com seis mil e quarenta e cinco volumes; entrando $n$ 'estes volumes algumas obras antigas de valor, e que estam ainda em bom estado; faltam porem todas as obras modernas, mesmo pertencentes á classe de Jurisprudência. Sobre Bellas-Letras quase nada possue ${ }^{13}$.

Se, como afirma Michel Espagne, "os lugares de concentração de livros estrangeiros são, ao mesmo tempo, os lugares de concentração do saber $^{\prime 14}$, estamos certamente diante de um fundo que procura se renovar segundo as exigências de seus leitores, a saber, uma elite de professores e de estudantes muito bem integrada no modelo de alta cultura fundada no sistema universitário europeu. Os livros estrangeiros, no caso em particular, as revistas especializadas em língua estrangeira, sugerem a existência de uma classe distinta de leitores proficientes em língua estrangeira, o que não era algo evidente naquele burgo. Aliás, a biblioteca

\footnotetext{
${ }^{13}$ Daniel Pedro Müller, Ensaio d'um quadro estatístico da província de São Paulo. Ordenado pelas leis provinciais

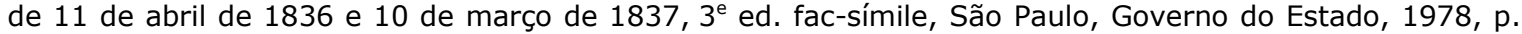
258 [Secretaria da Academia Jurídica de S. Paulo, 16 de Dezembro de 1836. Ildefonso Xavier Ferreira, Official Guarda Livros servindo de secretario o fez].

${ }^{14}$ Michel Espagne, "Transferência cultural e história do livro", Livro - Revista do Núcleo de Estudos do Livro e da Edição, Cotia, Ateliê Editorial, n. 2, 2012, pp. 21-34.
} 
terá o papel de alimentar intelectualmente a fome dessa nova elite que ancora na velha São Paulo, representando, nesse sentido, a possibilidade de inovação sem, contudo, romper com a tradição classista de detentora dos bens culturais. Deve-se ainda salientar que a evolução da coleção por meio de novas entradas, entre livros e periódicos, constitui um fator decisivo para o bom funcionamento do curso jurídico ${ }^{15}$. E, mais importante, os livros estrangeiros testemunham o desenvolvimento do comércio livreiro da capital e seus pontos de contato com importadores, embora tenha sido este o aspecto mais frágil a ser observado. Afinal de contas, malgrado o anúncio entusiástico da presença de revistas estrangeiras no acervo da Biblioteca, sabemos que o comércio da cidade era muito frágil, quase inexistente não fosse a ação de alguns vendedores a retalho. Tudo precisava vir da Corte do Rio de Janeiro, o que demandava tempo e encarecia os produtos.

Em 1857, a cidade não contava mais do que 30000 habitantes, embora apresentasse um corpo mais sólido de profissionais liberais, entre médicos, advogados, engenheiros, capitalistas e uma rede em desenvolvimento de serviços públicos. O crescimento demográfico de São Paulo será significativo apenas a partir de 1870, demonstrando seu primeiro grande salto na virada do século ${ }^{16}$. Mas a biblioteca revela novas orientações. O Catálogo das Obras Jurídicas da Faculdade de Direito de São Paulo, de 1857, elaborado pelo bibliotecário Luís Eugenio Barbosa, apresenta informações bem mais completas: autor, título (na língua original), formato, edição e número de volumes. Omite-se ainda o local de edição. O inventário se concentra apenas nas aquisições recentes na área jurídica, o que confirma a vontade de constituição de uma biblioteca especializada ${ }^{17}$.

As entradas mais importantes correspondem às edições impressas no período de 1800 a 1857 . Se se considera o fundo de origem, cujas bibliotecas remontavam às coleções religiosas do Antigo Regime, são evidentes as dificuldades de renovação do acervo. Alguns números dão bem uma ideia desse esforço: dos 107 títulos novos especializados e de autores contemporâneos, contam-se 31 para a área de direito político, 39 para direito administrativo e 10 de jurisprudência. Aliás, vale ressaltar que os antigos e pesados in-folio foram substituídos pelos mais flexíveis in- $8^{\circ}$, seguindo uma tendência geral do mercado.

Em 1872, um novo inventário, agora apresentado ao diretor da instituição com um quadro sinóptico, permite-nos uma apreciação mais completa da coleção ${ }^{18}$. De 9682 volumes inventariados, 6634 (68,5\%) representam edições em língua estrangeira. Entre os títulos em português

\footnotetext{
15 O público leitor deveria ser muito escasso. No mesmo recenseamento de 1836 o autor anuncia uma população urbana na ordem de 21933 habitantes, dentre os quais apenas " 1009 pessoas [cifra com uma precisão surpreendente] sabiam ler e escrever". Daniel Pedro Müller. Ensaio d'um quadro estatístico da província de São Paulo, cit, p. 11.

16 Em 1872: 31385 hab.; em 1890: 64 934; em 1900: 239 820; em 1920: 579 033. Synopse do recenseamento realizado em 1 de setembro de 1920 - População do Brazil, Rio de Janeiro, Ministério da Agricultura, Indústria e Commercio, Instituto de Expansão Comercial, 1926, p. 183.

17 Manuscritos do Arquivo da Faculdade de Direito de São Paulo [MAFD], Livro 18.

18 Repartição dos livros por assunto, formato e ano de edição; Quadro estatístico do acervo da Biblioteca 1872 [por Francisco de Souza Dias Ribeiro, bibliotecário]. MAFD, Livro 152, f. 60.
} 
$(31,4 \%)$, a maior parte foi impressa no Brasil $(65,5 \%)$. As edições nacionais são, logicamente, as mais recentes e se concentram no campo das leis: trata-se, muito provavelmente, da publicação de professores da Faculdade de São Paulo e do Recife. Além disso, a coleção apresenta seções mais gerais, nas quais a presença estrangeira é mais importante: Literatura, Poesia, Romance e Novelas, sem esquecer os periódicos, anuários e almanaques.

\begin{tabular}{|c|c|c|c|c|c|c|c|c|}
\hline & \multicolumn{2}{|c|}{\begin{tabular}{|c|} 
Impressos em língua \\
nacional
\end{tabular}} & \multicolumn{2}{|c|}{$\begin{array}{c}\text { Impressos em língua } \\
\text { estrangeira }\end{array}$} & \multicolumn{2}{|c|}{$\begin{array}{c}\text { Impressos no } \\
\text { Império }\end{array}$} & \multicolumn{2}{|c|}{ Total } \\
\hline & Obras & Vols. & Obras & Vols. & Obras & Vols. & Obras & Vols. \\
\hline Almanacks e annuarios & 91 & 280 & 1 & 9 & 90 & 261 & 92 & 289 \\
\hline Agricultura & 28 & 52 & 25 & 145 & 6 & 9 & 53 & 197 \\
\hline Biographias & 37 & 46 & 29 & 169 & 3 & 3 & 66 & 215 \\
\hline Diplomacia & 6 & 10 & 17 & 88 & 4 & 10 & 23 & 98 \\
\hline Direito e Jurisprudencia & 692 & 1.154 & 602 & 1.532 & 495 & 941 & 1.294 & 2.686 \\
\hline Estatística & 168 & 396 & 1 & 1 & 168 & 396 & 169 & 397 \\
\hline Historia & 161 & 416 & 254 & 1.069 & 22 & 78 & 415 & 1.485 \\
\hline Jornaes & 53 & - & 1 & - & 53 & - & 54 & - \\
\hline Lusicologia e Philologia & 26 & 50 & 121 & 245 & 7 & 10 & 147 & 295 \\
\hline Litteratura & 36 & 51 & 104 & 314 & 30 & 35 & 140 & 365 \\
\hline Mappas e Atlas & 9 & 9 & 20 & 21 & 9 & 9 & 29 & 30 \\
\hline Marinha e Navegação & - & - & - & - & - & - & - & - \\
\hline Mathematicas & 28 & 33 & 20 & 29 & 13 & 15 & 48 & 62 \\
\hline Medicina & 20 & 20 & 38 & 94 & 14 & 14 & 58 & 114 \\
\hline Philosophia & 4 & 6 & 66 & 186 & 3 & 3 & 70 & 192 \\
\hline Poesias & 19 & 19 & 46 & 112 & 10 & 10 & 65 & 131 \\
\hline Obras Juridicas & 40 & 233 & 26 & 805 & 29 & 190 & 66 & 1.038 \\
\hline Rethorica e Poetica & 1 & 1 & 14 & 15 & - & -1 & 15 & 16 \\
\hline Romances e novelas & 1 & 3 & 5 & 22 & - & - & 6 & 25 \\
\hline Sciencias Naturaes & 5 & 11 & 63 & 224 & - & - & 68 & 235 \\
\hline Theatro & 1 & 12 & 13 & 49 & - & - & 14 & 61 \\
\hline Theologia & 74 & 223 & 454 & 1.234 & 2 & 2 & 528 & 1.457 \\
\hline Viagens & 6 & 8 & 48 & 186 & 5 & 7 & 54 & 194 \\
\hline Geographia & 9 & 15 & 27 & 85 & 3 & 4 & 36 & 100 \\
\hline Somma & 1.515 & 3.048 & 1.995 & 6.634 & 966 & 1.997 & 3.510 & 9.682 \\
\hline
\end{tabular}

Figura 3. Quadro sinóptico do acervo da Biblioteca da Faculdade de Direito de São Paulo (1872)

Fonte: Bibliotheca da Faculdade de Direito de São Paulo. 31 de Dezembro de 1872.

Francisco de Souza Dias Ribeiro.

Sabemos que o enriquecimento do fundo depende, todavia, da inserção de São Paulo no mercado internacional. Nos anos 1860-70, a estrada de ferro liga, enfim, o porto à capital. Uma vez mais os caracteres geográficos de São Paulo - um nó natural de convergência das rotas terrestres e fluviais - fazem da cidade um importante centro de ligação entre o interior e o mar, o que significa o alto potencial de atração de riquezas, em um momento importante de desenvolvimento da economia agroexportadora baseada na cafeicultura. Em outros termos, a riqueza das exportações se converte em infraestrutura urbana. Fala-se em ciclo virtuoso da economia, o qual atrai negociantes estrangeiros ativos no comércio a varejo, de modo geral, em produtos finos importados, dentre os quais os livros se encaixam perfeitamente. Deve-se ainda considerar a emergência de uma nova burguesia ciosa pelas novidades europeias, particularmente as francesas ${ }^{19}$. É nesse momento, inclusive, as que transferências culturais entre a França e o Brasil se ampliam: não se trata mais de um grupo restrito de eruditos que cultivam as letras francesas,

\footnotetext{
${ }^{19}$ Marisa Midori Deaecto, Comércio e vida urbana na cidade de São Paulo (1889-1930), São Paulo, Senac, 2002 ; Pierre Monbeig, « La Croissance de la ville de São Paulo », Revue de géographie alpine, 1953.
} 
mas de uma fração mais ampla da sociedade para a qual a literatura francesa tem um papel importante em sua formação cultural. A Biblioteca, preservando-se ainda como a principal instituição de leitura da cidade, torna-se o epicentro dessas mutações ${ }^{20}$.

\section{A biblioteca e a cidade: entre o passado e o futuro}

Em 1887, a Biblioteca conhece seu primeiro e mais completo catálogo impresso. Nessa data a instituição comemora seu $60^{\circ}$ aniversário e a Faculdade de Direito se afirma como o epicentro da vida cultural e política do país. No entanto, a apresentação do catálogo contrasta como o otimismo esperado em uma tal efeméride:

Por esta simples enumeração se manifesta que a bibliotheca, formada sem gosto e sem escolha, com as livrarias dos frades franciscanos, do bispo da Ilha da Madeira, D. Luiz Rodrigues Vilhares, do bispo de S. Paulo, D. Matheus de Abreu Pereira, e com os legados de 700 volumes pelo primeiro director o Tenente-Coronel Arouche, e de 295 pelo desembargador Manoel da Cunha de Azevedo Coutinho Souza Chichorro, e com outras doações de menos importância, continúa, apezar da acquisição posterior de algumas obras, a permanecer no mesmo estado de pobreza em que se achava em 1881, quando o director de então, conselheiro Vicente Pires da Mota, que por muito tempo tinha sido lente da Faculdade, assim se exprimia a seu respeito:

'A bibliotheca é pobríssima de obras raras, e não pode ministrar auxílio para se acompanhar o progresso e desenvolvimento que diariamente apresentam as sciencias jurídicas: carece dos autores mais notaveis, e nem sequer possue algumas das inumeras revistas, que se publicam no estrangeiro.'

Na realidade, é digno de se lamentar que, estando a bibliotheca em um edificio com vastas accomodações para salas de leitura, com entrada independente, de modo a poder ser visitada a qualquer hora, não se a enriqueça de obras novas e importantes, que a elevem ao nível do desenvolvimento actual das sciencias; melhorando-se-lhe ao mesmo tempo o serviço em vantagem para a Faculdade e para esta capital, que ainda não possue uma bibliotheca publica!

Sóbe de ponto o reparo, quando se considera que, pertencendo a mesma bibliotheca á uma Faculdade, onde se dá o ensino sobre as sciencias sociaes e jurídicas, a classe - Jurisprudencia - que para este estabelecimento devêra ser a mais rica, seja entretanto menos abundante que a de Historia e Geographia e a de Sciencias e Artes.

\footnotetext{
${ }^{20}$ Novas bibliotecas abertas ao público passam a surgir a partir da década de 1860 , sobretudo por iniciativa de clubs, sociedades e instituições de ensino privado. É preciso igualmente levar em conta a ação da maçonaria, por exemplo, a Biblioteca da Sociedade Propagadora, cujo objetivo era o de propagar o ensino gratuito, técnico ou profissional, inclusive, com a oferta de aulas noturnas; ou, ainda, a Bibliotheca Germania, fundada pelos imigrantes alemães. Os poderes públicos investirão em uma nova instituição de porte apenas em 1895, já sob os auspícios da República. De acordo com o recenseamento de 1891, havia "na capital duas bibliotecas públicas, a da Faculdade de Direito do Largo S. Franciso e a do Liceu de Artes e Ofícios". Marisa Midori Deaecto, O Império dos livros... cit., pp. 228-238.
} 
[assinado: Antonio de Pádua Fleury. S. Paulo, 11 de Agosto de 1887]. ${ }^{21}$

Embora o diretor exagere nas colocações pouco festivas, fazendo, inclusive, críticas duras ao quadro geral da sociedade, bem no clima da campanha republicana que não demoraria a colocar abaixo a monarquia brasileira, ele nos oferece, todavia, uma ideia da importância da instituição para a comunidade de leitores da capital ${ }^{22}$. Afinal de contas, somos testemunha de que as correspondências dos bibliotecários dão conta de um esforço diário para o enriquecimento do acervo! É verdade que o grosso das aquisições se deve às doações feitas pelos lentes ou por seus herdeiros. Mas, observamos, igualmente, que na medida em que a cidade se desenvolvia, os bibliotecários buscavam estreitar seus laços com os livreiros locais e com alguns comissários de importação e exportação, logrando obter livros a preços convidativos, mais baixos do que os oferecidos pelo mercado carioca.

Após a aquisição, em 1882, do célebre Manuel du libraire et de l'amateur de livres de Brunet ${ }^{23}$, os métodos de classificação dos livros vão pouco a pouco se aprimorando. É bem provável, aliás, que a execução de um catálogo completo e impresso, como o publicado em 1887, já estivesse nos planos do bibliotecário no momento em que ele arrematou aquele importante manual. Alguns meses após a sua aquisição, vemos o bibliotecário Fernando Mendes d'Almeida anunciar a recepção de uma encomenda contendo 81 volumes:

os livros chegaram em muito bom estado, todos solidamente encadernados, conforme recomendei, sendo que a edição das obras completas de Cujacio (Ventiis et Mutince 1758-1783) é a mais estimada. A colleção Dalloz - jurisprudence générale - ficou completa até 1880 , e a encadernação dos volumes relativos aos seus últimos annos foi feita tal qual a dos anteriores existentes n'esta Bibliotheca ${ }^{24}$.

A compra feita por intermédio da empresa de comissão Victor Nothmann \& Cie. custou aos cofres da Faculdade o montante de 590\$620. Um mês mais tarde, novo relatório, dando conta do pagamento de outra fatura

importancia de noventa e seis mil setecentos e vinte reis (96\$720), quantia por elles despendida com a compra e mais despezas de dezesseis obras em vinte e um volumes, todos muito bem encadernados, como os da primeira remessa, sendo que a fatura confere com os volumes por mim recebidos, em três do corrente $[\ldots]^{25}$.

\footnotetext{
${ }^{21}$ Catálogo impresso das obras adquiridas pela Faculdade de Direito, 1887. São Paulo: Seckler, 1887.

${ }^{22}$ Teologia, 751 títulos; Jurisprudência, 1018 ; Ciências e Artes, 1100 ; Belas Letras, 510 ; História e Geografia, 1237.

${ }^{23}$ Jacques Charles Brunet, Manuel de libraire et de l'amateur de livres, contenant..., $6^{\mathrm{e}}$ éd., Paris, Firmin Didot Frères, $1860-1865,6$ vol.

${ }^{24}$ MAFD, Livro 18, f. 2.

${ }^{25}$ MAFD, Livro 18 , f. 3.
} 
No final deste ano auspicioso o bibliotecário viria ainda a apresentar nova fatura, no valor de $226 \$ 800$ pela compra de 16 títulos, em 29 volumes $^{26}$. É claro que as movimentações não se dão todos os dias com a mesma naturalidade, pois as chamadas "demandas reprimidas" são menos raras do que os bibliotecários certamente desejariam que fossem e as relações com os livreiros nem sempre são pacíficas.

É verdade que com o passar dos tempos os bibliotecários se especializaram nesta tarefa, por assim dizer, mercadológica, tornando-se mais exigentes e seletivos. Negociavam com os principais livreiros da cidade e da capital fluminense. Cientes da concorrência aberta entre as livrarias instaladas em São Paulo e o tradicional mercado fluminense, eles lograram obter abatimentos sobre os preços expostos nos catálogos dos comerciantes locais. Não são raras as ocasiões em que mantêm contato direto com livreiros-editores internacionais e o fazem à medida que as condições infraestruturais e financeiras se mostravam favoráveis para a importação direta de gêneros estrangeiros.

Para tanto, demonstravam notável destreza em diversos níveis de negociação. Além do benefício de desconto sobre os preços expostos nos catálogos, que chegava a $20 \%$, discutiam as condições de importação e de pagamento das faturas, não ignorando os vários fatores que oneravam as tramitações: "direitos de importação, despachos, carretos e frete na estrada de ferro", além da usual "comissão de $10 \%$ à proporção do total real do débito"27.

Tal habilidade só pode ser justificada devido à rotina de trabalho, que exigia dos funcionários da Biblioteca e, em especial, do bibliotecáriochefe, único interlocutor desta seção da Faculdade com a diretoria, maior intimidade com os negócios do livro.

Vale notar que todos estes relatórios, petições, comunicados, demandas reprimidas, orçamentos, listas de preços, notas fiscais, pedidos de importações, correspondências de livrarias, assinaturas estrangeiras, permutas, enfim, esta enorme variedade de escritos integrava-se pouco a pouco ao expediente da repartição.

Noutros termos, a Biblioteca da Faculdade de Direito se modernizava.

\section{Conclusão}

Esperamos com esse artigo colocar em evidência a história da Biblioteca Pública de São Paulo, no curso do século XIX. Não se trata,

\footnotetext{
${ }^{26}$ Ibidem.

27 "Tendo tido ordem do finado Director da Faculdade de Direito, o Exmo. Conselheiro Vicente Pires da Motta para mandar buscar na Europa diversas obras com destino á Bibliotheca, encommendei-as à Bruhns e Cia., negociantes d'esta praça sob as cláusulas seguintes: 1 a. Serem compradas pelos preços dos cathalogos com o abatimento de vinte a vinte por cento, conforme o costume dos livreiros de Paris; 2a. Virem todas encadernadas simplesmente em bezerro ou carneiro; 3a. Receber a dita firma a comissão de dez por cento pelo seo trabalho sobre o total das despezas até a entrega [...] Ilmo. Exmo. Snr. Conselheiro Dr. Director da Faculdade de Direito de São Paulo André Augusto de Padua Fleury. Assinado por Fernando Mendes de Almeida; o ajudante, João Martins da Silva". MAFD 18, folha 7.
} 
evidentemente, de se traçar um processo linear e constante de constituição de um fundo, mas de observar, em suas grandes linhas, as contribuições de períodos distintos à luz das tendências intelectuais e das possíveis relações entre a cidade e os livros.

Não é por acaso que o primeiro período traduz, grosso modo, a preponderância religiosa, o que faz com que a coleção contraste com os discursos fortemente liberais dos anos de 1820-30. No segundo momento, observamos o esforço de constituição dos regulamentos da Biblioteca e do seu acervo. Na última fase, a Biblioteca olha para o passado e tenta vislumbrar seu futuro, evidenciando-se uma articulação mais estreita entre a cidade e a comunidade acadêmica, o que provoca uma tomada de posição mais clara da instituição frente às questões políticas de seu tempo.

É verdade que toda coleção supõe a presença de frequentadores qualificados, entre bibliotecários, diretores, professores e estudantes. Nesse sentido, a Biblioteca deve responder a horizontes de expectativas por vezes distintos: tentamos na medida do possível identificar esses horizontes, por meio da leitura de documentos diversos.

Como resultado deste processo não linear e desigual de acumulação de livros, observamos no quadro estatístico de 1891 que a Biblioteca apresenta uma coleção substanciosa de obras jurídicas e históricas, ao passo que os livros de belas-letras, sempre tão numerosos nas coleções de particulares e nos catálogos de livreiros, não pareciam ter espaço privilegiado nesta instituição. Afinal, embora se tratasse da única Biblioteca pública que a cidade conheceu até o ano de 1895, desde as suas origens seu perfil se definira pelo próprio espaço que ela vinha ocupar. Era a Biblioteca das Arcadas e esta marca sem dúvida repercutiu sobre o acervo. ${ }^{28}$

Confirmam esta tendência o número de títulos e os temas mais consultados no ano de 1890/91:

4.202 obras de Jurisprudência; 620 de Historia e Geographia; 460 de Sciencias e Artes; 205 de Belas Artes; 60 de Teologia. Liam-se mais livros ou periódicos em francês (2.230 obras) do que em português (2.154). ${ }^{29}$

\footnotetext{
${ }^{28}$ Isto não quer dizer que a fase de abastança não fosse por vezes refreada por períodos de infortunada escassez: "A Bibliotheca, conforme o mappa que vae junto, não adquirio uma só obra por ser exígua a verba destinada á acquisição de obras, e pelos embaraços que sempre encontra o bibliothecario tendo-se limitado a assignaturas de Revistas e Jornaes.

O número de doadores também não foi avultado, e nem com elles deve contar uma repartição de tal ordem.

A reencadernação de obras em avultado número é uma das necessidades mais urgentes, pois será um crime deixar que as traças consummão verdadeiras preciosidades que possue a Bibliotheca; para isso, porém é preciso mais do que a ação do Bibliothecário.

Os srs. lentes e os srs. consulentes clamam todos os dias pela falta completa de obras novas [...] em tempo oportuno organizei, com o auxilio de algum lente, uma lista das obras mais indispensaveis de suas respectivas cadeiras e remetti-as a $V$. Exa. sem que nenhuma providencia tivesse sido tomada; julgo uma necessidade a encomenda dessas obras. Até esta data a Bibliotheca não possue a colleção completa das leis da República, apesar de já ter eu dirigido-me ao Sr. Ministro do Interior, a V. Exa. o Director da Imprensa Nacional, ao Director da Bibliotheca Nacional [...]. assinado Joaquim Mendonça Filho". Relatório anual de 1895. MAFD, Livro 18, folha 18.

${ }^{29}$ Ibidem, folha 66.
} 
No espírito das reformas republicanas, também esta instituição se adequou às novas orientações de uso dos espaços públicos:

De $1^{0}$ de julho em diante, em cumprimento do novo regulamento de 2 de janeiro de 1891, a Bibliotheca é franqueada ao público, das 9 horas ás 2 horas da tarde, e das 6 horas ás 20 horas da noite. [ass. o Bibliothecario Antonio Teixeira da Silva $]^{30}$.

Na virada do século, a Biblioteca aparece renovada e mantém seu status no meio intelectual planaltino.

\section{Referências}

ADÃo, Aurea. Estado absoluto e ensino das primeiras letras: escolas régias (1772-1794). Lisboa: Calouste Gulbenkian, 1997.

THE AMERICAN Peoples Encyclopedia: a modern reference work. New York: Grolier Inc., 1968.

ANSELMO, Artur. Estudos de história do livro. Lisboa: Guimarães Editora, 1997.

BANSFIELD, Edward. Needed: a public purpose. In: The Public library and the city, Boston (Mass.), M.I.T. Press, 1966, p. 104;

BARBIER, Frédéric. Em France: le prive et le public, ou qu'est-ce qu'une bibliothèque des Lumières?. UN'ISTITUZIONE DEI LUMI: la biblioteca. Teoria, gestione e pratiche biblioteconomiche nell'Europa dei Lumi. 2011, Parma. Actes du congrès international, Parme, Biblioteca Palatina, 20-21 maio 2011, Parma, Caratteri, 2013. p. 10-28.

BARBOSA, Luís Eugenio. O Catálogo das Obras Jurídicas da Faculdade de Direito de São Paulo. São Paulo, 1857.

BRASIL. Biblioteca Nacional. Anais da Biblioteca Nacional. Rio de Janeiro, n. 74, v. II, 1953.

BRASIL. Ministério da Agricultura, Indústria e Commercio. Instituto de Expansão Comercial. Synopse do recenseamento realizado em 1 de setembro de 1920: população do Brazil, Rio de Janeiro, p. 183, 1926.

BERTRAND, Anne-Marie. Bibliothèque publique et public library: essai de généalogie comparée. Villeurbanne: ENSSIB, 2010.

BRUNET, Jacques Charles. Manuel de libraire et de l'amateur de livres, contenant. 6 éd., Paris: Firmin Didot Frères, 1860-1865, 6 vol.

CARVALHO, Gilberto Vilar de. Biblioteca Nacional (1807-1990): biografia. Rio de Janeiro: Irradiação Cultural, 1994, p. 40.

DEAECTO, Marisa Midori. Comércio e vida urbana na cidade de São Paulo (1889-1930). São Paulo, Senac, 2002.

${ }^{30}$ Idem, ibidem. 
DEAECTO, Marisa Midori. Império dos livros: instituições e práticas de leituras na São Paulo oitocentista. São Paulo, Edusp, 2011, p. 87.

ELLIS, Myriam. Documentos sobre a primeira biblioteca oficial de São Paulo. Revista de História, São Paulo, n. 30, p. 400-447, 1957.

ESPAGNE, Michel. Transferência cultural e história do livro. Livro - Revista do Núcleo de Estudos do Livro e da Edição, Cotia, Ateliê Editorial, n. 2, 2012, pp. 21-34.

MARCÍLIO, Maria Luiza. La Ville de São Paulo: peuplement et population, 1750-1850 d'après les registres paroissiaux et les recensements anciens. Paris: PUF, 1968.

MORAES, Rubens Borba de. Livros e bibliotecas no Brasil Colonial. Rio de Janeiro, Livros Técnicos e Científicos; São Paulo, Secr. da Cultura, Ciência e Tecnologia do Estado de São Paulo, 1979, p. 143-144;

MONBEIG, Pierre. La Croissance de la ville de São Paulo. Revue de géographie alpine. 1953.

MULLER, Daniel Pedro. Ensaio d'um quadro estatístico da província de São Paulo: ordenado pelas leis provinciais de 11 de abril de 1836 e 10 de março de 1837. 3 ed. fac-símile. São Paulo: Governo do Estado, 1978, p. 258.

ROWER, Basílio. Páginas da história franciscana. Petrópolis: Vozes, 1971, p. 134 ;

UNIVERSIDADE DE SÃO PAULO. Arquivo. Manuscritos do Arquivo da Faculdade de Direito de São Paulo. São Paulo: USP, [s.d.]. Livros 18 e 152. 